\title{
Adsorptive Removal of Toxic Metal from Aqueous Solution by Using a Biowaste -Used Tea Leaves
}

\author{
Bindra Shrestha, P.L. Homagai, M.R. Pokhrel and K.N. Ghimire \\ Central Department of Chemistry \\ Tribhuvan University, Kirtipur, Kathmandu \\ e-mail: binraghu@yahoo.com
}

\begin{abstract}
In the present work an efficient and cost-effective biosorbent was prepared by chemical modification of tealeaves. Amine-functional group was introduced on the surface of adsorbent using dimethylamine. The adsorbent was characterized by SEM, FTIR and elemental analysis. The adsorption capacity of the adsorbent for Cd (II) was determined as the function of $\mathrm{pH}$ of the solution, concentration of metal ions and contact time. The maximum adsorption was found to be $77 \mathrm{mg} / \mathrm{g}$ at $\mathrm{pH} 6$.
\end{abstract}

Key words: amination, biosorbent, cadmium, Langmuir isotherm

\section{Introduction}

Environmental pollution by heavy metals is of major concern, because of their toxicity and bioaccumulating tendency. They threat human life and the environment (Nurchi et al. 2008). Cadmium is a non-essential and non-beneficial element to plants and animals. It is one of the priority pollutant and included in 'the big three' (most toxic) heavy metals (Volesky et al. 1995). The toxicity of cadmium in human health includes disfuntioning of kidney, hepatic damage, hypertension and itai-itai disease (Igwe et al. 2006).

To remove heavy metals from wastewater various conventional methods like chemical precipitation, filtration, flocculation, reverse osmosis, coagulation, ion exchange, ultra filtration and electrochemical deposition were used (Babel et al. 2003). But these conventional methods become non-efficient and nonfeasible when concentration of the metal is in trace amount ranging from 1-100 mg/l. In such cases adsorption process using agricultural waste as biosorbent can be used as an attractive alternative for wastewater treatment ( Ayyappan et al. 2005).

Biosorbents are prepared from naturally abundant waste biomasses which are economically acceptable. They have high metal adsorption capacity and can be reused after desorption of metal ions. Many researchers have been investigating new biosorbents like sugarcane bagasse (Homagai et al. 2011), orange waste (Biswas et al. 2007), saw dust (Basso et al. 2002), olive stone (Blazquez et al. 2005), sea weeds (Ghimire et al. 2007), wheat straw (Chen et al. 2010) and chitin (Jeon et al. 2004) for the removal of heavy metals from wastewater. In the present study used tealeaves have been used as a biowaste for the removal of Cd (II) from aqueous solution. The biosorbent was aminated to introduce amino-functional group on the surface of the adsorbent. The effectiveness of adsorbent was studied by determining the maximum adsorption capacity using batch method.

\section{Methodology}

Fifty grams of used tealeaves was washed with hot distilled water till the filtrate became clear. The biowaste was dried in an oven at $70^{\circ} \mathrm{C}$. The dried mass was treated with concentrated sulphuric acid, which dissolved the soluble substances and expossd the surface of biopolymer for further treatment. This acid treated biowaste was washed thoroughly with distilled water till the filtrate became neutral and dried in an oven. The charred biowaste was mixed with thionyl chloride $\left(\mathrm{SOCl}_{2}\right)$ in presence of pyridine at $0^{\circ} \mathrm{C}$. The mixture was heated at $70^{\circ} \mathrm{C}$ for 2 hrs and cooled. The remaining thionyl chloride was decomposed with ice. The sample was filtered and washed with distilled 
water followed by propanol and dried. The chlorinated sample was then aminated by dimethylamine in presence of dimethylsulphoxide (DMSO) and sodium carbonate at $70^{\circ} \mathrm{C}$ for 6 hrs. The mixture was cooled, filtered and washed with $0.1 \mathrm{M} \mathrm{HCl}$ followed by distilled water. Finally the adsorbent was washed with propanol and dried in an oven at $70^{\circ} \mathrm{C}$ for $24 \mathrm{hrs}$. The aminated adsorbent is called aminated tealeaves (ATL).

The $1000 \mathrm{mg} / \mathrm{l}$ stock solution of Cd (II) was prepared by dissolving calculated amount of Cadmium nitrate [Cd $\left(\mathrm{NO}_{3}\right)_{2} \cdot 4 \mathrm{H}_{2} \mathrm{O}$ ] in $0.1 \mathrm{M} \mathrm{HNO}_{3}$. The stock solution was diluted to required dilution to prepare working solution of different concentration. The $\mathrm{pH}$ of experimental solutions were maintained using nitric acid and sodium hydroxide and [2-4-(2hydroxymethyl)-1-piperazinyl] ethanesulphonic acid [HEPES] was used as buffer. Analytical grade reagents $[A R]$ were used for all experimental works.

The adsorption experiments were studied by using batch sorption experiments. All the experiments were performed at $25^{\circ} \mathrm{C}$ and $150 \mathrm{rpm}$ on a mechanical shaker with $25 \mathrm{mg}$ of adsorbent in $50 \mathrm{ml}$ conical flask containing $20 \mathrm{ml}$ of Cd (II) solution. The effect of $\mathrm{pH}$ of the solution, initial concentration and contact time were studied. After adsorption, the mixture was filtered through Whatman filter paper (no. 40). The concentration of Cd (II) in solution before and after equilibrium was determined by atomic absorption spectrophotometer (AAS) using air acetylene flame.

The adsorption efficiency A\% of the adsorbent was calculated by using equation (1)

$$
A \%=\frac{C_{i}-C_{e}}{C_{i}} \times 100
$$

where $\mathrm{C}_{\mathrm{i}}$ and $\mathrm{C}_{\mathrm{e}}$ are concentration of metal ions in $\mathrm{mg} /$ $\mathrm{l}$ before and after adsorption experiments. The amount of metal adsorbed i.e. sorption capacity $q_{e}(\mathrm{mg} / \mathrm{g})$ was computed by using equation (2)

$$
q=\frac{\mathrm{C}_{i}-\mathrm{C}_{\mathrm{e}}}{\mathrm{W}} \mathrm{XV}
$$

where $\mathrm{V}$ is volume of metal solution (l) and $\mathrm{W}$ is weight of adsorbent (g).

\section{Results and Discussion Characterization}

To enhance the adsorption capacity of the biosorbent, it was chemically modified with dimethylamine. It is supposed that the alcoholic and phenolic $\mathrm{OH}$ groups present in cellulose, hemicellulose and lignin of the biosorbent are substituted with amino-functional groups. The amino-functional groups have been found to be more effective chelating group for adsorption of metals from aqueous solution. The $\mathrm{N}$ atom of the functional group has greater tendency to donate a lone pair of electrons for sharing with metal ions to form a metal complex. Hence, there has been considerable interest for introduction of $\mathrm{N}$-functional group on the surface of adsorbent to enhance the adsorption capacity. In this study aminofunctional group was introduced on the surface of the bioadsorbent by using dimethylamine. The aminated biosorbent was characterized by scanning electron microscopy (SEM), fourior transform infrared spectroscopy (FTIR) and elemental analysis.

\section{Scanning electron microscopy}

The scanning electron microscopic images were used to examine the surface morphologies of waste tealeaves before and after chemical modification (Sankaramakrishnan et al. 2006). The images are given in Fig. 1. Initially the surface of biosorbent is smooth with uniform microporous structure which becomes rough after amination indicating the modification of the adsorbent.

\section{Fouir-transform infrared spectroscopy}

In FTIR analysis, each specific chemical bond often shows a unique energy absorption band and it has been used as a useful tool to identify the presence of certain functional groups on the surface of the biosorbent (Shriner et al. 1998). The FTIR spectra of TL and ATL are shown in Fig. 2. The spectra are complex due to numerous different types of functional groups on the surface of adsorbent. In the spectrum of TL, the peaks can be assigned as follows, $3388 \mathrm{~cm}^{-1}$ was due to $\mathrm{OH}$ stretching, $2924 \mathrm{~cm}^{-1}$ due to $\mathrm{CH}$ stretching in $\mathrm{CH}, \mathrm{CH}_{2}$ and $\mathrm{CH}_{3}$ groups, $1646 \mathrm{~cm}^{-1}$ due to $\mathrm{C}=\mathrm{O}$ stretching in carbonyl group and $1078 \mathrm{~cm}^{-}$ ${ }^{1}$ due to $\mathrm{C}-\mathrm{O}$ stretching. After chemical modification the spectrum exhibits some significant changes. The broad band ranging from about 3118 to $3650 \mathrm{~cm}^{-1}$ corresponds to the combination of stretching vibration bands of both $\mathrm{OH}$ and $\mathrm{NH}$ groups suggesting that $\mathrm{N}$ functional groups are introduced on the surface of the 
biosorbent. The peaks at $1450 \mathrm{~cm}^{-1}$ and $1033 \mathrm{~cm}^{-1}$ are due to the $\mathrm{C}-\mathrm{H}$ bending and $\mathrm{C}-\mathrm{N}$ stretching, respectively. The increase in percentage of nitrogen

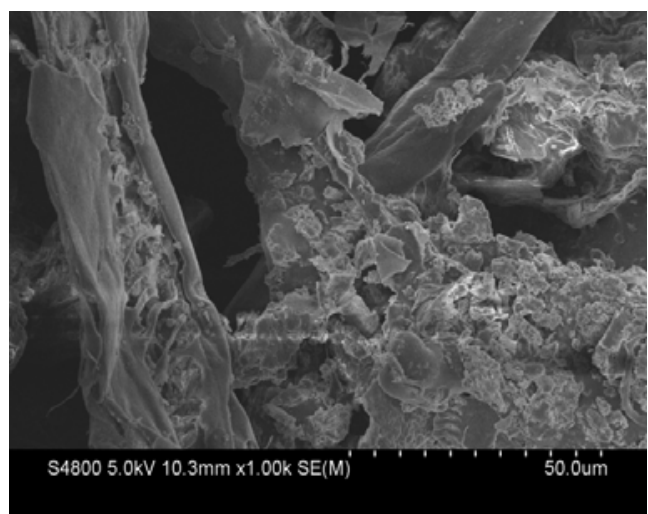

1(a) in elemental analysis of ATL 5.56\% than in TL 1.03\% also further supports the introduction of amine functional groups on the surface of biosorbent after chemical modification.

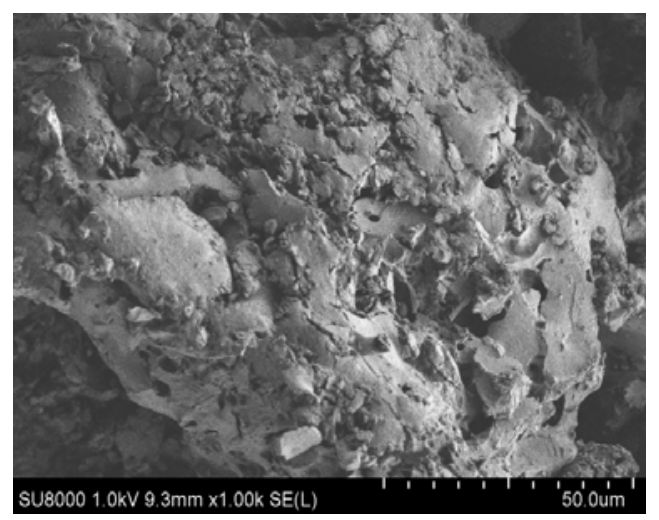

1(b)

Fig. 1. SEM images of tealeaves (TL) and aminated tealeaves (ATL)

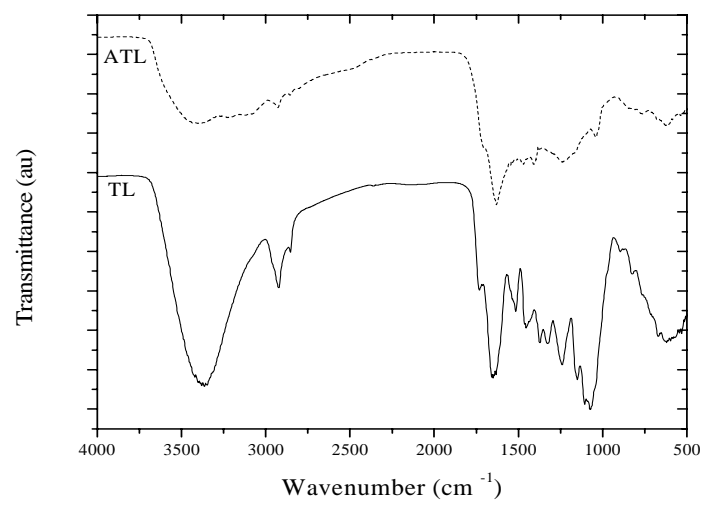

Fig. 2. FTIR spectra of tealeaves (TL) and aminated tealeaves (ATL)

\section{Effect of pH}

The adsorptive removal of metal ions from aqueous solution is dependent on the $\mathrm{pH}$ of the solution as it affects the surface charge of the adsorbent, the degree of ionization and the species of adsorbate. To study the effect of $\mathrm{pH}$ on the Cd (II) removal efficiency the $\mathrm{pH}$ of the solution was varied from 1-6. As shown in Fig. 3, adsorption increases with increase of $\mathrm{pH}$ and maximum removal of $\mathrm{Cd}$ (II) was observed at $\mathrm{pH}$ 6. On further increase in $\mathrm{pH}$ precipitation occured. At low $\mathrm{pH}$, protons would compete for the binding sites with metal ions. The protonation of adsorbent surface tends to decrease the metal sorption. At higher $\mathrm{pH}$ concentration of protons decreases and the surface of the adsorbent became negative which increases the adsorption of metal ions. The solubility of metal ions also decrease at higher $\mathrm{pH}$ facilitating the adsorption. The further increase of $\mathrm{pH}$ results in precipitation of metal ions as hydroxides.

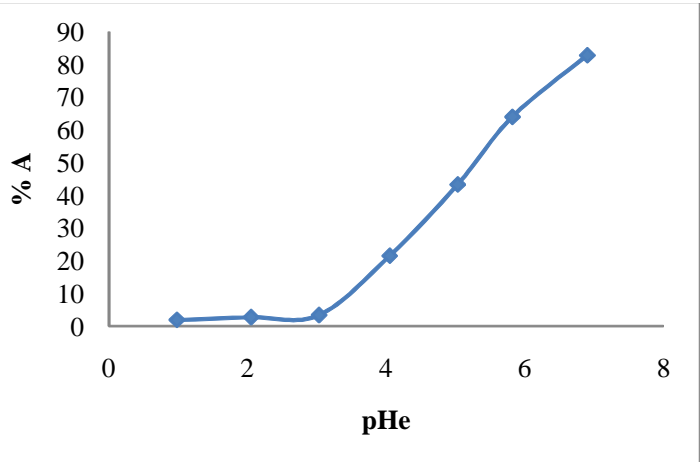

Fig. 3. Effect of pH on adsorption of Cd (II) onto ATL

\section{Effect of initial concentration}

The study of adsorption isotherm indicates the adsorption capacity of the adsorbent at experimental condition. Fig. 4. shows the plot for the adsorption isotherm. In the plot, the adsorption of metal ions increases initially with increase in equilibrium metal concentration. The uptake of metal ions is eventually limited by the occupied active sites and results in a plateau. It suggests that metal ions are adsorbed according to Langmuir model. The linear form of Langmuir isotherm is given by equation (3)

$$
\frac{C_{e}}{q_{e}}=\frac{1}{q_{m} b}+\frac{C_{e}}{q_{m}}
$$




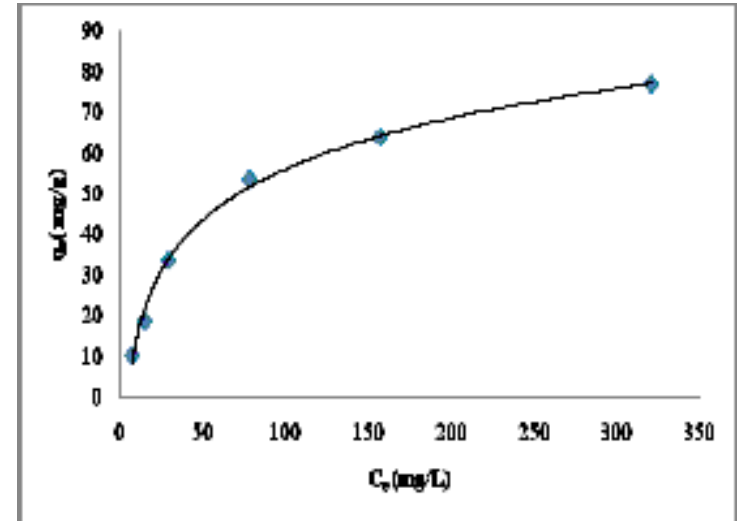

Fig. 4. The adsorption isotherm of Cd (II) onto ATL

where $\mathrm{q}_{\mathrm{e}}$ is amount adsorbed ( $\mathrm{mg} / \mathrm{g}$ ), $\mathrm{C}_{\mathrm{e}}$ is equilibrium concentration of metal ions (mg/l) and $\mathrm{q}_{\mathrm{m}}$ and $\mathrm{b}$ are Langmuir constants. The linear plot of $\mathrm{C}_{\mathrm{e}} / \mathrm{q}_{\mathrm{e}}$ versus $\mathrm{C}_{\mathrm{e}}$ as shown in Fig.5. suggests the applicability of Langmuir adsorption model and indicates the formation of monolayer coverage of metal ions on the surface of adsorbent.

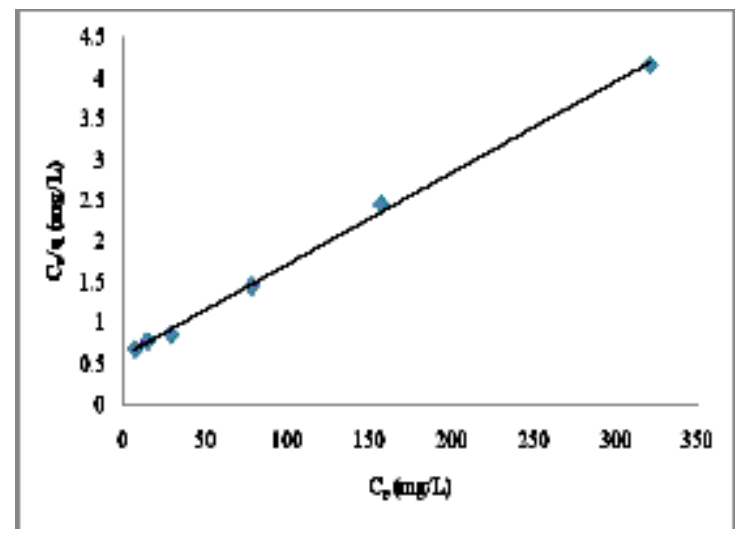

Fig. 5. Langmuir isotherm plot for the adsorption of Cd (II) onto ATL

\section{Effect of contact time - kinetics of adsorption}

Adsorption kinetics is studied to evaluate the efficiency of adsorption. The effect of contact time on adsorption of Cd (II) onto ATL is shown in Fig. 6. The plot consists of initial rapid adsorption phase and a slower phase where equilibrium uptake was achieved. The initial high rate of adsorption of metal ions is due to free active binding sites on the surface of the adsorbent. As the number of available sites decrease the rate of adsorption of metal ions also decrease.

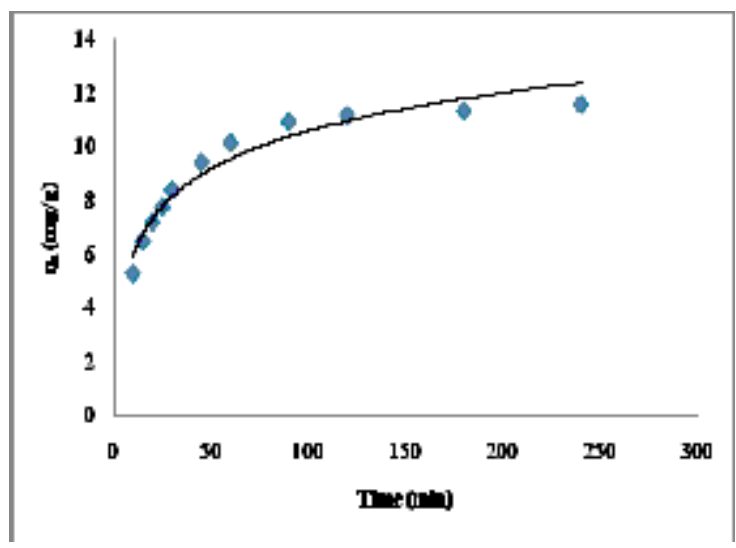

Fig. 6. Adsorption kinetics for Cd (II) onto ATL

To describe the kinetics of adsorption pseudo-second order kinetic model is applied (Ho et al. 1999). It is expressed as

$$
\frac{t}{q_{\mathrm{t}}}=\frac{1}{K_{2} q_{e}^{2}}+\frac{\mathrm{t}}{q_{e}}
$$

where $\mathrm{q}_{\mathrm{t}}$ is the amount adsorbed at time $\mathrm{t}(\mathrm{min})$ and $\mathrm{k}_{2}$ $(\mathrm{g} / \mathrm{mg} / \mathrm{min})$ is the rate constant of pseudo-second order kinetics of adsorption. The plot of $t / q_{t}$ versus $t$ is given in Fig. 7.

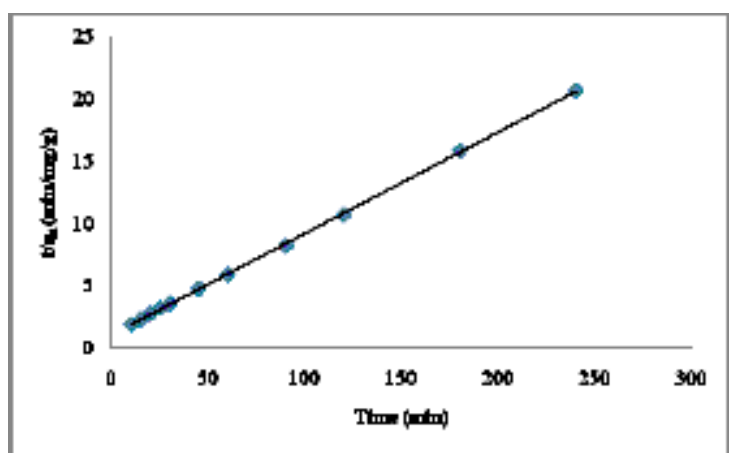

Fig. 7. Pseudo-second order kinetics Cd (II) onto ATL

The plot is a straight line with high correlation coefficient value. It indicates that pseudo-second order kinetic model can be applied for adsorption of Cd (II) onto ATL and also indicates the chemisorption of the metal ion.

In present work $\mathrm{N}$-functional group was successfully introduced onto the surface of biosorbent. The adsorbent was characterized with SEM, FTIR and 
Bindra Shrestha et al./Adsorptive removal of toxic.......

elemental analysis. The adsorption capacity was studied as the function of $\mathrm{pH}$ of the solution, concentration of the solution and contact time. The maximum loading capacity for Cd (II) was found to be $77 \mathrm{mg} / \mathrm{g}$. Hence, the aminated tealeaves can be used as an efficient biosorbent for removal of Cd (II) from wastewater.

\section{Acknowledgements}

One of the authors, B. Shrestha, gratefully acknowledges Nepal Academy of Science and Technology (NAST), Nepal, for providing Ph.D. fellowship to carry out this research work.

\section{References}

Ayyappan, R., A.C. Sophia, K. Swaminathan, S. Sandhya. 2005. Removal of $\mathrm{Pb}$ (II) from aqueous solution using carbon derived from agricultural wastes. Process Biochem. 40:1293-1299.

Babel. S. and T.A. Kurniawan. 2003. Low- cost adsorbents for heavy metals uptake from contaminated water: a review. J. Hazard. Mater. B97: 219-243.

Basso, M.C., E.G. Cerrella and A.L. Cukierman. 2002. Lignocellulosic materials as potential biosorbent of trace toxic metals from waste water. Ind. Eng. Chem. Res. 41: 3580-3585.

Biswas, B.K., K. Inoue, K.N. Ghimire, S. Ohto and H. Kawakita. 2007. The adsorption of phosphate from an aquatic environment using metal loaded orange waste. J. Colloid Interface Sci. 312: 214- 1223.

Blazquez, G., F. Hernainz, M. Calero and L.F. Ruiz-Nunez. 2005. Removal of cadmium ions with olive stones: the effect of some parameters. Process Biochem. 40: 26492654.
Chen, S., Q. Yue, B. Gao and X. Xu. 2010. Equilibrium and kinetic adsorption study of the adsorptive removal of Cr (VI) using modified wheat residue. J. Collid and Interface Sci. $\quad 349:$ 256-264.

Ghimire, K.N., K. Inoue, K Ohto and T. Hayashida. 2007. Adsorptive separation of metallicpollutants onto waste seaweeds, Porphyra yezoensis and Ulva japonica. Sep. Sci. and technol., 42:2003-2018.

Ho, Y.S. and G. McKay. 1999. Pseudo-second order model for sorption process. Process Biochem. 34: 451465

Homagai, P.L., K.N. Ghimire and K. Inoue. 2011. Preparation and characterization of charred xanthated sugarcane bagasse for the separation of heavy metals from aqueous solution. Sep. Sci. Technol., 46:1-10.

Igwe, J.C. and A.A. Abia. 2006. A bioseparation process for removing heavy metals from waste water using biosorbents. American J. Biotechnol. 5(12):11671179.

Jeon, C. and W.H. Holl. 2004. Application of the surface complexation model to heavy metal sorption equilibria onto aminated chitosan. Hydrometallurgy 71:421428.

Nurchi, V.M. and I. Villaescusa. 2008. Agricultural biomasses as sorbents of some trace metals. Coordination Chemistry Reviews 252:1178-1188.

Sankaramakrishnan, N. and R. Sanghi. 2006. Preparation and characterization of a novel xanthated chitosan. Carbohy. Poly. 66:160-167.

Shriner, R.L., C.K.F. Hermann, T.C. Morill, D.Y. Curtin and R.C. Fuson. 1998. The systematic identification of organic compounds. Seventh ed. Wiley, New York.

Volesky, B. and Z.R. Holan. 1995. Biosorption of heavy metals. Biotechnol. Prog. 11:235-250. 
Nepal Journal of Science and Technology Vol. 13, No. 2 (2012) 109-114 